\title{
Center for Catalysis
}

\author{
Dr. George A. Kraus, Director
}

The funds have been used to support proposals from interdisciplinary research teams in areas related to catalysis and green chemistry. The funds were used for seed projects. Research results from these seed projects have already led to publications and successfully funded grant proposals. These publications and grant titles are listed at the end of the report. Additional proposals based on results obtained from the seed projects will continue to be submitted. As a result of the funding the Center for Catalysis has expanded by six new faculty participants.

\section{Summaries of research results}

\section{Photocatalytic Heterogeneous Oxidation Of Hydrocarbons}

Principal Investigators: Andreja Bakac, Brent Shanks, Marek Pruski, Victor Lin Goal(s): To develop a working system for photocatalytic oxidation of hydrocarbons based on heterogeneous uranyl catalysts and utilizing (a) visible light as an inexpensive energy source and (b) environmentally friendly oxidants, such as molecular oxygen. Such photocatalysts would be useful in chemical synthesis and destruction of wastes. Results: Uranyl ions were supported on mesoporous-silica by a co-condensation method under acidic conditions. The silica- $\mathrm{U}_{\mathrm{aq}} \mathrm{O}_{2}{ }^{2+}$ material was characterized by powder X-Ray Diffraction, BET analysis, and SEM imaging, and the uranium content was determined by ICP-MS. Excitation with visible or near-UV light of aqueous suspensions of silica$\mathrm{U}_{\mathrm{aq}} \mathrm{O}_{2}{ }^{2+}$ generates an excited state that decays with $\mathrm{k}_{0}=1.5 \times 10^{4} \mathrm{~s}^{-1}$. Under slow steadystate photolysis in $\mathrm{O}_{2}$-saturated suspensions, silica- $\mathrm{U}_{\mathrm{aq}} \mathrm{O}_{2}{ }^{2+}$ acts as a photocatalyst for the oxidation of alcohols with $\mathrm{O}_{2}$.

\section{Oxidation and Oxidative Degradation}

Principal Investigators: William Jenks and James Espenson

Goal(s): New chemical and photochemical oxidation reactions under Green Chemistry conditions were to be developed with two goals, to form useful reaction products and degrade harmful ones, with inexpensive and environmentally benign metal catalysts, with oxidants that do not generate wastes, in non-polluting solvents, perhaps water.

Results: This project has been successful on two fronts, both with respect to the removal of harmful compounds from aqueous systems; research is ongoing along both lines. The Espenson results focused on the catalytic oxidation of chlorophenols. These compounds are used as wood preservatives, pesticides, and disinfectants, and are listed as priority pollutants because of their tenacity. The oxidation of trichlorophenol by hydrogen peroxide is accelerated by light as generally innocuous as ambient room light. This was found both for the slow un-catalyzed reaction and for reactions catalyzed by various iron(III) complexes. The acceleration was attributed to photochemical reactions of benzoquinones that are formed by thermal reactions.

The published Jenks group work focused on mechanistic issues in the degradation of organic compounds using $\mathrm{TiO}_{2}$ photocatalysts. It was reported in 2003 that $\mathrm{TiO}_{2}$ photocatalytic chemistry does not include the type of addition chemistry at phosphorus that is observed for the reaction of hydroxyl radicals with sulfur, despite the similarity in 
chemistry between $\mathrm{TiO}_{2}$ photocatalysis and $\mathrm{HO} \bullet$ in a more general sense. The compounds were models for various herbicides, pesticides, and nerve agents.

\section{Catalytic Conversion of Corn Fiber to Hydrogen}

Principal Investigators: Brent H. Shanks, Victor S.-Y. Lin, Marek Pruski

Goal(s): The two primary objectives for the proposed project were (1) demonstrate the efficacy of hydrolyzing oligosaccharides, which have been released by the hydrothermal treatment of corn fiber to monosaccharides using nanostructured catalysts, and (2) demonstrate the subsequent conversion of the monosaccharides to hydrogen using catalytic liquid-phase reforming.

Results: Propyl thiol-functionalized silica catalysts were synthesized by co-condensation of tetraethoxysilane with 3-(mercaptopropyl)trimethoxysilane using surfactant-mediated supramolecular assembly. The propyl thiol group was subsequently oxidized using hydrogen peroxide to form the propylsulfonic acid moiety as shown in Figure 1. These catalysts had textural properties corresponding to a surface area of $740 \mathrm{~m}^{2} / \mathrm{g}$, pore volume of $0.95 \mathrm{~cm}^{3} / \mathrm{g}$, and median pore diameter of $52 \AA$. The ion exchange capacity of the catalyst was $1.2 \mathrm{H}^{+} \mathrm{meq} / \mathrm{g}$.

Hydrolysis experiments were performed with the solid acid catalyst and several different

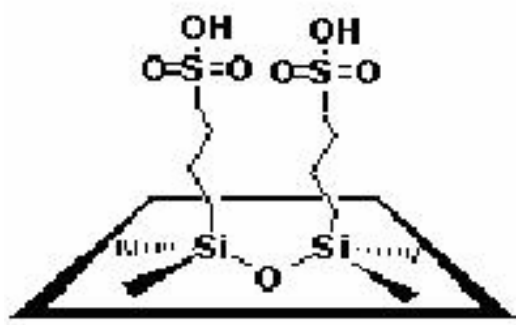

Figure 1: Propylsulfonic acid functional site. disaccharides (cellobiose, maltose, lactose). In the experiments, the concentration of the disaccharide in deionized water was $1 \mathrm{wt} \%$ and of the solid acid catalyst was $0.4 \mathrm{wt} \%$. The reaction temperature was ramped from 100 $160^{\circ} \mathrm{C}$ at a rate of $2^{\circ} \mathrm{C} /$ minute. The hydrolysis rates for the disaccharides were found to be similar.

\section{Combinatorial Development of Homogeneous Transition Metal Catalysts Using Molecular Evolution}

Principal Investigator: L. Keith Woo

Goal(s): Single-stranded DNA will be developed through in vitro evolution (Systematic Enhancement of Ligands by EXponential enrichment or SELEX) to produce highly effective aqueous chemical catalysis with transition metal cofactors. A primary goal is to demonstrate proof-of-concept in the application of in vitro evolution methods to the development of single-stranded DNA-transition metal-based catalysts in a model system. Results: We have shown that single-stranded DNA can be developed through in vitro evolution (SELEX) to produce a new system of aqueous chemical catalysts. In our original proposal we initially intended to target cyclopropanation as the test reaction. However, difficulties in preparing key intermediates led us to focus on the Heck reaction

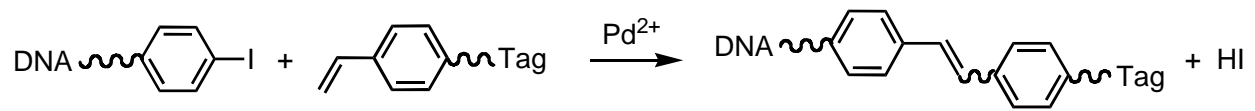

(eq. 1). This proved to be more amenable and allowed us to make significant progress. We were successful in demonstrating our goal that molecular evolution (SELEX) can be applied to catalytic processes for organic reactions. However, additional research will 
continue. For example, our linkage between the DNA strand and the iodophenyl substrate is a relatively short 19-atom chain. We suspect that this is too short to provide optimal catalytic activity and will be examining much longer linkages (up to 120 atoms). In addition, we are beginning to clone and sequence our evolved DNA catalysts in order to study structural aspects.

\section{Proposals based on our results have been submitted to funding agencies}

"Selective and Efficient Catalysis In 3-D Controlled Mesoporous Environments" (co-PI's: Pruski, Lin, Bakac, Espenson, Angelici) has been funded by the DOE (Catalysis Science grant No AL 03380 011).

“Mechanisms of Photocatalytic Degradation” (Jenks) submitted to NSF.

"Enhanced Recovery of Sugars from Corn Fiber and Distillers Dry Grains - Iowa Biotechnology Byproducts Consortium,” (PI, B.H. Shanks, co-PI, L.A. Johnson), USDA, $\$ 50,000,8 / 04-7 / 05$.

"Development of Sustainable Biobased Products and Bioenergy in Cooperation with the Midwest Consortium for Sustainable Biobased Products and Energy," (Prime - Purdue University, ISU PI, B.H. Shanks), USDOE, \$112,000 (ISU portion), 7/04-6/06.

\section{Publications based on our results}

Nieweg, J.A., Woldegiorgis, K.L., Lin, V.S.Y., and Bakac, A., "Mesoporous SilicaSupported Uranyl: Synthesis and Photoreactivity," manuscript in preparation

Oh, Y.-C.; Li, X.; Cubbage, J. W.; Jenks William, S. "Mechanisms of Catalyst Action in the $\mathrm{TiO}_{2}$-mediated Photocatalytic Degradation of Maleic and Fumaric Acid" Appl. Catal. B: Environmental 2004, 54, 105-114.

Oh, Y.-C.; Bao, Y.; Jenks, W. S. "Isotope Studies of Photocatalysis. TiO2-Mediated Degradation of Dimethyl Phenylphosphonate" J. Photochem. Photobiol. A 2003, 160, 69-77.

Oh, Y.-C.; Jenks, W. S. "Photocatalytic Degradation of a Cyanuric Acid, a Recalcitrant Species" J. Photochem. Photobiol. A 2004, 162, 323-328.

Lente, G.; Espenson, J. H. "Photoaccelerated oxidation of chlorinated phenols" Chemical Communications 2003, 1162-1163.

Lente, G.; Espenson, J. H. "A kinetic study of the early steps in the oxidation of chlorophenols by hydrogen peroxide catalyzed by a water-soluble iron(III) porphyrin" New Journal of Chemistry 2004, 28, 847-852.

Lente, G.; Espenson, J. H. "Photoreduction of 2,6-dichloroquinone in aqueous solution. Use of a diode array spectrophotometer concurrently to drive and detect a photochemical reaction" Journal of Photochemistry and Photobiology, A: Chemistry 2004, 163, 249-258. 